\title{
Administration of angiotensin II and a bradykinin B2 receptor blocker in midpregnancy impairs gestational outcome in guinea pigs
}

Gloria Valdés ${ }^{1,2^{*}}$, Daniela Schneider ${ }^{1}$, Jenny Corthorn ${ }^{1,2}$, Rita Ortíz ${ }^{1}$, Stephanie Acuña ${ }^{1}$ and Oslando Padilla ${ }^{3}$

\begin{abstract}
Background: The opposing renin-angiotensin system (RAS) and kallikrein-kinin system (KKS) are upregulated in pregnancy and localize in the utero-placental unit. To test their participation as counter-regulators, circulating angiotensin II (All) was exogenously elevated and the bradykinin B2 receptor (B2R) was antagonized in pregnant guinea-pigs. We hypothesized that disrupting the RAS/KKS balance during the period of maximal trophoblast invasion and placental development would provoke increased blood pressure, defective trophoblast invasion and a preeclampsia-like syndrome.
\end{abstract}

Methods: Pregnant guinea-pigs received subcutaneous infusions of All $(200 \mu \mathrm{g} / \mathrm{kg} / \mathrm{day})$, the B2R antagonist Bradyzide (BDZ; 62.5 microg/kg/day), or both (All + BDZ) from gestational day 20 to 34. Non-pregnant cycling animals were included in a control group (C NP) or received All + BDZ (All + BDZ NP) during 14 days. Systolic blood pressure was determined during cycle in C NP, and on the last day of infusion, and 6 and 26 days thereafter in the remaining groups. Twenty six days after the infusions blood and urine were extracted, fetuses, placentas and kidneys were weighed, and trophoblast invasion of spiral arteries was defined in the utero-placental units by immunocytochemistry.

Results: Systolic blood pressure transiently rose in a subgroup of the pregnant females while receiving All + BDZ infusion, but not in All + BDZ NP. Plasma creatinine was higher in All- and BDZ-treated dams, but no proteinuria or hyperuricemia were observed. Kidney weight increased in All + BDZ-treated pregnant and non-pregnant females. Aborted and dead fetuses were increased in dams that received All and All + BDZ. The fetal/placental weight ratio was reduced in litters of All + BDZ-treated mothers. All groups that received interventions during pregnancy showed reduced replacement of endothelial cells by extravillous trophoblasts in lateral and myometrial spiral arteries.

Conclusions: The acute effects on fetal viability, and the persistently impaired renal/placental sufficiency and incomplete arterial remodeling implicate the RAS and KKS in the adaptations in pregnancy. The results partially confirm our hypothesis, as a preeclampsia-like syndrome was not induced. We demonstrate the feasibility of characterizing systemic and local modifications in pregnant guinea-pig, supporting its use to study normal placentation and related disorders.

Keywords: Renin-angiotensin system, Kallikrein-kinin system, Pregnant guinea-pig, Gestational systemic blood pressure regulation, Utero-placental units, Pregnancy outcomes

\footnotetext{
*Correspondence: gvaldes@med.puc.cl

${ }^{1}$ Centro de Investigaciones Médicas, Escuela de Medicina, Pontificia

Universidad Católica, Santiago, Chile

${ }^{2}$ Departamento de Nefrología, Escuela de Medicina, Pontificia Universidad

Católica, Santiago, Chile

Full list of author information is available at the end of the article
} 


\section{Background}

The renin-angiotensin system (RAS) has traditionally been considered the main vasopressor stimulus. This was because angiotensin II (AII), which was considered the terminal peptide of the RAS, exerts a potent effect when binding to its AT1 receptor (AT1R). However, the functional scope of the RAS and the number of its participants have now been extended [1] by non-proteolytic RAS activation through the renin/prorenin receptor [2], a vasodilating receptor of AII (AT2R) and several intermediate vasodilatory peptides/receptors, including angiotensin-(17)/Mas, angiotensin-(3-8) or AIV/AT4R, and angiotensin(1-9)/AT2R [3-7].

The kallikrein-kinin system (KKS) includes both a plasma and a tissue cascade. Plasma kallikrein is synthesized in the liver, released into circulation, and activated by coagulation factor XII to liberate bradykinin and lys-bradykinin from high-molecular-weight kininogen. The main tissue kallikrein, KLK1, is synthetized in various organs and releases lys-bradykinin by cleaving low-molecular-weight kininogen. Kinins activate the main constitutive B2 receptor (B2R) and the $\mathrm{B} 1$ receptor, the latter of which is scarcely expressed in normal tissues and is mainly induced by tissue injury, endotoxins, or cytokines [8]. The tissue KKS has a vasodepressor role, which has been unmasked by converting enzyme inhibitors [9-11] and blockers of its main vasodilatory constitutive receptor, the bradykinin B2R [12].

The enzymatic cascades of the RAS and the KKS are virtually mirror images of each other. Bradykinin and angiotensin II enhance angiogenesis while angiotensinogen is antiangiogenic [13], and the angiotensin II/AT1R and bradykinin/B2R pathways are proinflammatory. However, both peptidergic systems have antagonic vasomotor and pleiotropic effects, impacting vascular smooth muscle, fibrosis, cardiovascular hypertrophy, platelet aggregation, oxidative stress and electrolyte balance. The two systems are ubiquitous and have endocrine, paracrine, and autocrine roles $[14,15]$. Moreover, they maintain active cross-talk at various sites, from activation of prorenin by kallikrein $[16,17]$ to heterodimerization of their main receptors AT1R and B2R [18-21]. Overall, their vasodilating peptides integrate a rich network of potentiating pathways [22].

During gestation, the RAS and the KKS are associated with up- or down-regulation of maternal blood pressure, and with auto/paracrine effects at the feto-maternal interface [19,23-26]. Moreover, in vitro, the invasive capacity of immortalized trophoblasts is impaired by angiotensin II [27] and enhanced by bradykinin B2R-mediated stimulation [28]. Thus, we believe that the RAS and KKS are interrelated antagonistic systems that should be jointly studied.

The guinea-pig is an attractive model for such studies, as it shares with humans an extensive vascular transformation [29], a hemomonochorial placenta, the temporal pattern of progesterone levels [30], a preeclamptic-like syndrome associated with reduced placental perfusion [31], a uteroplacental repertoire of vasoactive and angiogenic factors in functionally equivalent structures [22,32-35] which includes the B1 and B2 [36] as well as the AT1 and AT2 bradykinin and angiotensin receptors respectively (Acuña and Valdés, unpublished observation).

Here we tested our hypothesis that disturbing the endogenous balance between the RAS and the KKS in pregnant guinea-pigs, during the period of maximal trophoblast invasion and placental development [37], by the administration of angiotensin II or Bradyzide - a potent non-peptide antagonist of the B2R [38] - would provoke a defective trophoblast invasion, fetal losses, blood pressure changes and preeclampsia-like morphological and functional alterations.

\section{Methods}

\section{Animals}

All experiments were conducted according to the Guide for the Care and Use of Laboratory Animals (National Research Council, USA), and were approved by the Institutional Review Board for Ethics and Animal Welfare, and by the Ethics Committee of FONDECYT (Fondo Nacional de Desarrollo Científico y Tecnológico, Chile).

Virgin Pirbright white guinea-pigs of $\sim 600 \mathrm{~g}$ were kept under controlled conditions of humidity and temperature $\left(25^{\circ} \mathrm{C}\right)$, with a 12-h light-dark cycle. Females were examined daily for perforation of the vaginal closure membrane. Upon this occurrence, they were caged with fertile males, and the following day was defined as day 1 . Between days 18-20, pregnancy was confirmed by ecography (Aloka Flexus SSD-1100; Hitachi Aloka Medical, Tokyo, Japan). On day 20, pregnant guinea-pigs were anesthetized with intraperitoneal ketamine $(60 \mathrm{mg} / \mathrm{kg})$ and xylazine $(4 \mathrm{mg} / \mathrm{kg})$ prior to subcutaneous implantation of Alzet 2ML2 osmotic pumps (Durect, Cupertino, CA) in the interscapular region.

Over 14 days, these pumps delivered either saline solution (control; $\mathrm{n}=6$ ), angiotensin II (Sigma) $200 \mu \mathrm{g} / \mathrm{kg} /$ day (AII; $\mathrm{n}=7$ ), Bradyzide (Sigma) $62.5 \mu \mathrm{g} / \mathrm{kg} /$ day $(\mathrm{BDZ} ; \mathrm{n}=5$ ), or angiotensin II plus Bradyzide (AII + BDZ; $n=6$ ). The dose of AII was subpressor, as determined in a pilot study in non-pregnant guinea-pigs. To evaluate the direct and the persistent consequences of the interventions, systolic blood pressure was determined during the last hours of the infusion on gestational day 34, and at 6 and 26 days after withdrawal of the osmotic pumps. Blood pressure was measured under anesthesia in the pad of the right paw compressed by a neonatal blood pressure cuff (Critikon, General Electric Healthcare, Connecticut, EEUU) using a Power Lab 8 SP system (ADInstruments, Sidney, Australia). Blood pressure data were analyzed with the Labchart graphic software 6.1 Pro (ADInstruments). After the blood pressure measurement on gestational day 34 , the osmotic pumps were extracted while the animals were still anesthetized. 
The study also included two groups of non-pregnant cycling guinea-pigs. The first group included control non-pregnant females (C NP; $n=5)$; in them the systolic blood pressure was measured in random days of the estrous cycle. The second group received subcutaneous infusions of AII + BDZ for 14 days (AII + BDZ $\mathrm{NP} ; \mathrm{n}=6$ ), and systolic blood pressure was measured on the last day of infusion, and at 6 and 26 days after its discontinuation.

On gestational day 60 or 26 days after AII + BDZ infusion in non-pregnant females, with the animals under ketamine and xylazine, urine was withdrawn from the bladder for determination of protein (Bradford method) and creatinine (Beckman Autoanalyser, Fullerton, CA) and blood from the left ventricle for creatinine and uric acid determination (Beckman Autoanalyser). Then the animals were euthanized with an overdose of ketamine/xylazine, and the uterus, feto-placental units, and kidneys were removed. The fetuses, placentas, and kidneys were weighed after trimming off the umbilical cord, amniotic membranes, and perirenal fat. Fetal loss was attributed to demise if an atrophic or necrotic feto-placental unit was observed, or to abortion when a fetus observed by ultrasonography was absent at term, since miscarriages in guinea-pigs are frequently not accompanied by persistence of the implantation site (Elger, personal communication). Only units with a live fetus were included for measurements of fetal and placental weight and for immunohistochemical studies. A central cross-section through the placenta, subplacenta, implantation site, and underlying myometrium was fixed as a single block. The placenta, and the subplacental decidua and myometrium were also isolated in other fetoplacental units; from these, the fetal/placental weight ratio was calculated as a marker of placental efficiency [39]. Tissues were immediately fixed with phosphate-buffered $10 \%$ formalin for $24 \mathrm{~h}$, then dehydrated in a graded series of ethanol and xylene dilutions, and embedded in ParaplastPlus $^{\oplus}$ (Sigma, St. Louis, MO). Sections $(6 \mu \mathrm{m})$ were mounted on silanized slides.

\section{Immunostaining procedure}

Immunostaining was performed at room temperature. Deparaffinized sections were rehydrated using ethanol, rinsed three times for five minutes each in phosphatebuffered saline with $50 \mathrm{mM}$ Tris- $\mathrm{HCl}$, and submitted to heat-induced antigen retrieval using citrate buffer ( $\mathrm{pH}$ 6.0). Endogenous peroxidases were blocked by incubation in $10 \% \mathrm{H}_{2} \mathrm{O}_{2}$ for ten minutes. Sections were then incubated in a humid chamber for $30 \mathrm{~min}$ with protein block (Cas-Block' Zymed, San Francisco, CA), followed by incubation for $18 \mathrm{~h}$ at $4^{\circ} \mathrm{C}$ with anti-pancytokeratin mouse monoclonal antibody (1:50, P2871, Sigma). Sections were immunostained using a biotin-streptavidinperoxidase system $\left(\mathrm{LSAB}+{ }^{\oplus}\right.$, DakoCytomation). Finally, the samples were treated for 15 min with $0.1 \%(w / v) 3-3^{\prime}$ diaminobenzidine in buffer containing $0.05 \% \mathrm{H}_{2} \mathrm{O}_{2}$. The slides were counterstained with Harris hematoxylin (Sigma).

\section{Evaluation of uterine arterial trophoblast invasion}

Spiral arteries were identified as lateral if localized in the periphery of the subplacenta, or myometrial if in the uterine smooth muscle below the placental bed. The extravillous trophoblast (EVT) was defined as intramural when located in the media of the spiral artery, and as endovascular when lining the lumen of the spiral artery and replacing endothelial cells. Photographic images were acquired with a Nikon CoolPix 4500 camera (Nikon Inc., Tokyo, Japan), coupled to a Zeiss AxioImager AX.10 microscope (Carl Zeiss, CA). The portion of the endovascular trophoblast replacing endothelial cells was calculated by measuring the arterial perimeter occupied by cytokeratin-positive cells, using Axiovision 4.8.2.0 LE (Carl Zeiss AG, Inc., Oberkochen, Germany). Groups were compared according to the percentage of intraluminal perimeter occupied by cytokeratin-positive cells in the lateral and myometrial spiral arteries.

\section{Statistics}

A Bayesian analysis [40] was performed to test differences between systolic blood pressures in different groups and periods and the proportion between viable versus lost fetuses according to treatment. Systolic pressure was modeled as a multivariate normal distribution with different mean vectors and variance-covariance matrices for groups and periods. Data are expressed as mean and dot-plot of individual values. The logarithm of the non-viable fetuses/ [1 - the predicted non-viable fetuses] was modeled as a normal distribution, with group-dependent median and variances. After proving that variances were similar among groups, a common variance was used. For each group, we calculated the proportion of viable fetuses, the differences between these proportions, and their credible intervals (CI). Data are expressed as proportion of live fetuses and CI. The analyses were performed with the open-source OpenBUGS program. Differences were considered significant when the CI did not cross zero.

A one-way ANOVA with Fisher's LSD post-hoc test was performed to determine the effects of the interventions on fetal, placenta, and kidney weights. Student's t-test was used to evaluate differences in the protein/creatinine index among the different groups of pregnant dams and the non-pregnant females that received AII + BDZ. Data are expressed as mean and dot-plot of individual values. Data were analyzed using Graphpad Prism 6.01 (GraphPad Inc., San Diego, CA) and were considered significantly different when $\mathrm{P}<0.05$. 


\section{Results}

\section{Maternal blood pressure}

Pregnant dams in gestational day 34, which were on the fourteenth day of AII + BDZ infusion, exhibited a dual effect; in them a group displayed a marked increase of systolic blood pressure while another maintained values within that of control animals and those receiving single infusions (Figure 1A). This elevation subsided after infusion cessation, such that the systolic blood pressure at gestational day 40 (not shown) and 60 were similar to those in the control and singly treated groups (Figure 1B). The blood pressure elevation induced by AII + BDZ in a subgroup of pregnant animals did not occur in AII + BDZ-treated nonpregnant females. (Figure 1A).

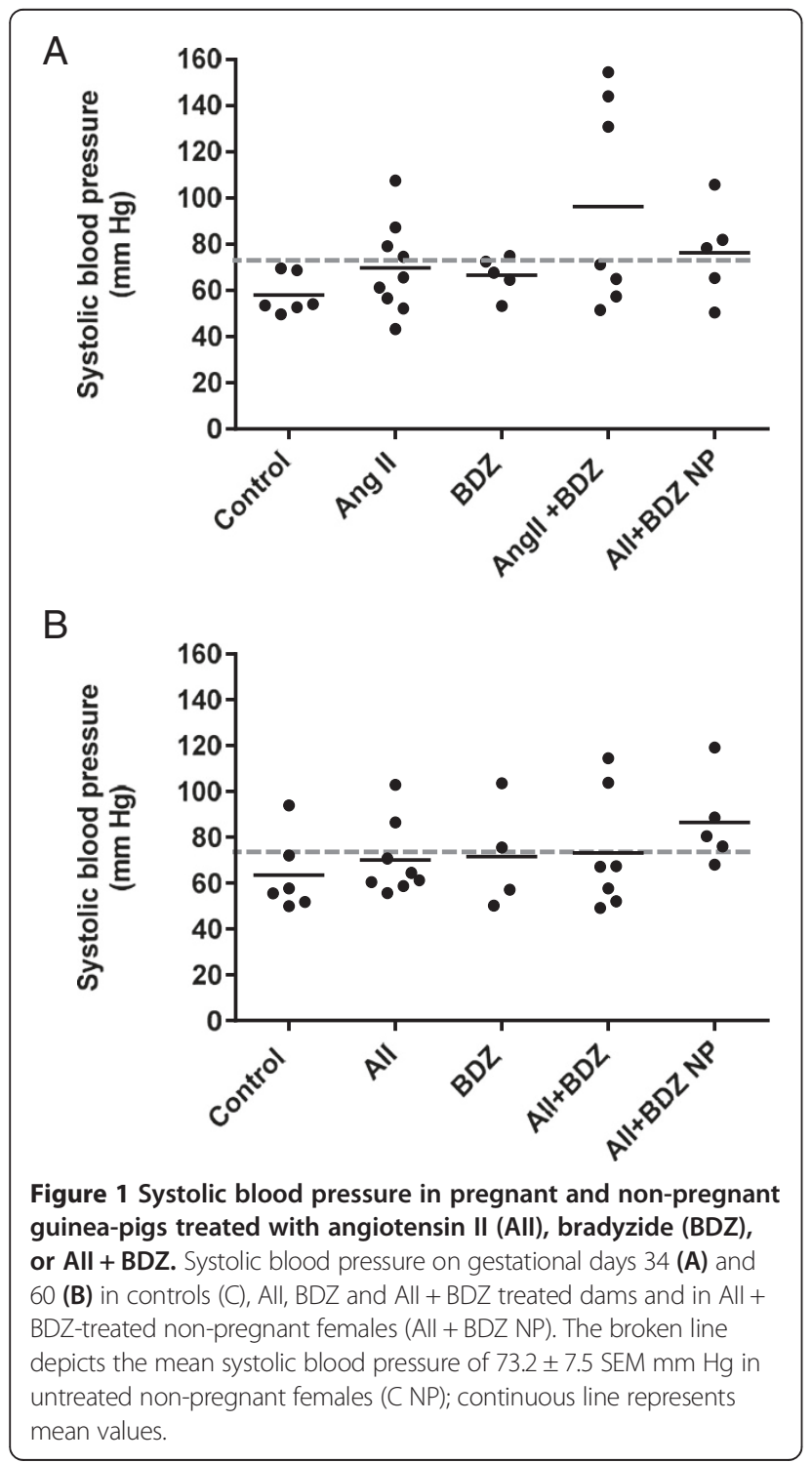

Fetal, placental, and maternal outcomes

The proportions of viable versus lost fetuses (including abortions and fetal demises) were reduced in the groups treated with AII (0.75; CI, 0.57-0.89) and with AII + BDZ (0.68; CI, 0.50-0.84) compared to the control group (0.95; CI, 0.8-0.99, $\mathrm{P}<0.05$ ); the ratio of viable/lost fetuses did not differ between the control and BDZ-treated groups (0.80; CI, 0.57-0.95). Infusions with BDZ and AII + BDZ were associated with reduced fetal weight, compared to animals infused with only AII $(\mathrm{P}<0.01)$ (Figure $2 \mathrm{~A})$. The fetal/placental weight ratio was also reduced in litters of mothers treated with $\mathrm{AII}+\mathrm{BDZ}$, compared to those of controls $(\mathrm{P}<0.05)$ and the AII group $(\mathrm{P}<0.01)$ (Figure $2 \mathrm{~B})$. The placental weights of the treated dams were not different from those of controls.

Kidney weights were similar in all groups. AII-treated dams had higher plasma creatinine levels than controls $(0.46 \pm 0.05$ versus $0.33 \pm 0.02 \mathrm{mg} / \mathrm{dl} ; \mathrm{P}<0.01)$. Both pregnant and non-pregnant animals receiving AII + BDZ presented reduced plasma creatinine levels compared with animals receiving single interventions $(0.38 \pm 0.02$ and
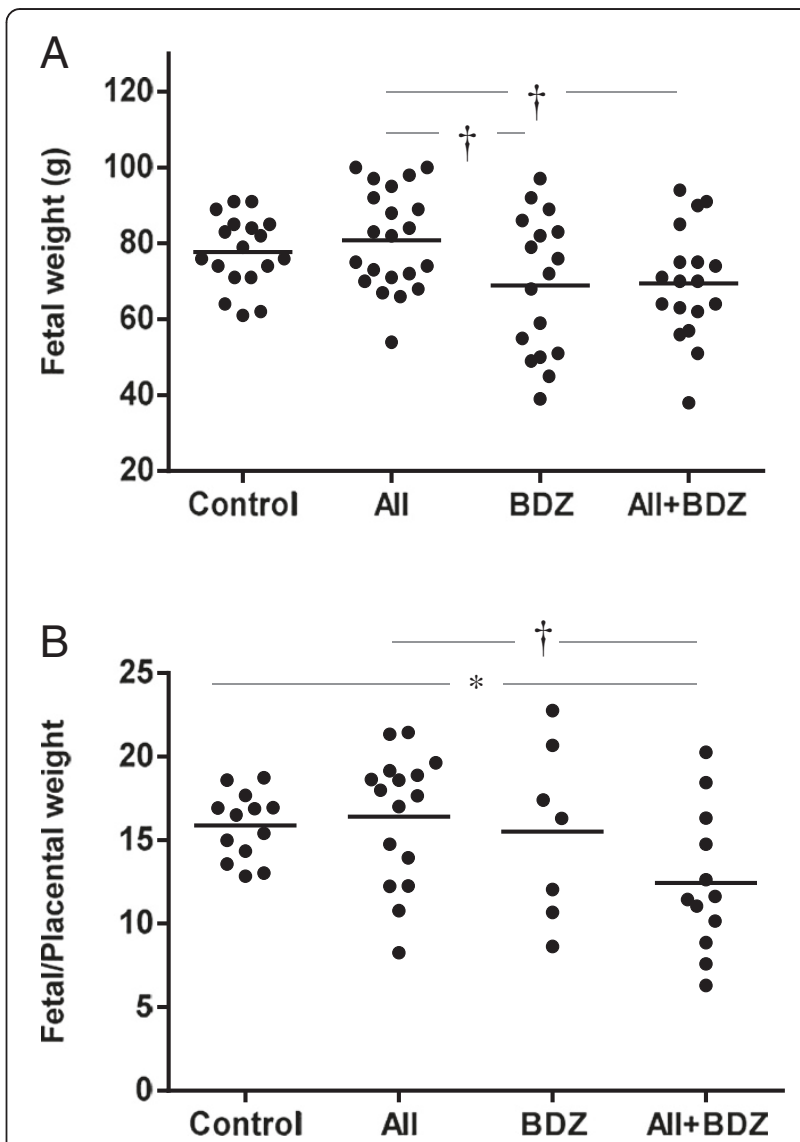

Figure 2 Fetal weight and fetal/placental weight ratios from dams treated with saline, angiotensin II (AII), Bradyzide (BDZ), or All + BDZ. (A) Fetal weight. (B) Fetal/placental weight ratio. Continuous line represents mean values. ${ }^{*} P<0.05 ;+P<0.01$. 
$0.36 \pm 0.02 \mathrm{mg} / \mathrm{dl}$ in comparison to $0.46 \pm 0.05$ and $0.48 \pm$ $0.04 \mathrm{mg} / \mathrm{dl}$ for AII and BDZ; $\mathrm{P}<0.05)$. Neither control, treated dams or non-pregnant AII + BDZ treated females exhibited proteinuria or hyperuricemia.

\section{Remodeling of uterine arteries}

In the lateral spiral arteries no intramural trophoblasts were observed; all treated groups exhibited decreased intraluminal replacement of endothelium by extravillous trophoblasts ( $\mathrm{P}<0.005$ for the AII-, AII + BDZ- and P $<0.0005$ for the BDZ-treated groups versus control) (Figure $3 \mathrm{~A}$ ). In myometrial spiral arteries, the perimeter occupied by endoluminal EVT was reduced in the groups receiving AII, BDZ, $(\mathrm{P}<0.0005$ for both) and AII + BDZ $(\mathrm{P}<0.005)$ as compared to controls. (Figure $3 \mathrm{~B}$ ). In summary, both the isolated and combined interventions resulted in reductions of endoluminal EVT in lateral and myometrial spiral arteries as depicted in Figure 4, upper and lower panel, respectively.

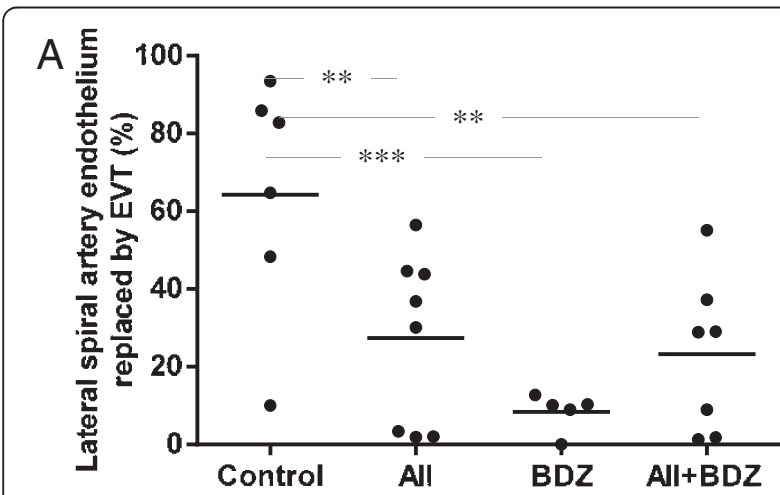

B

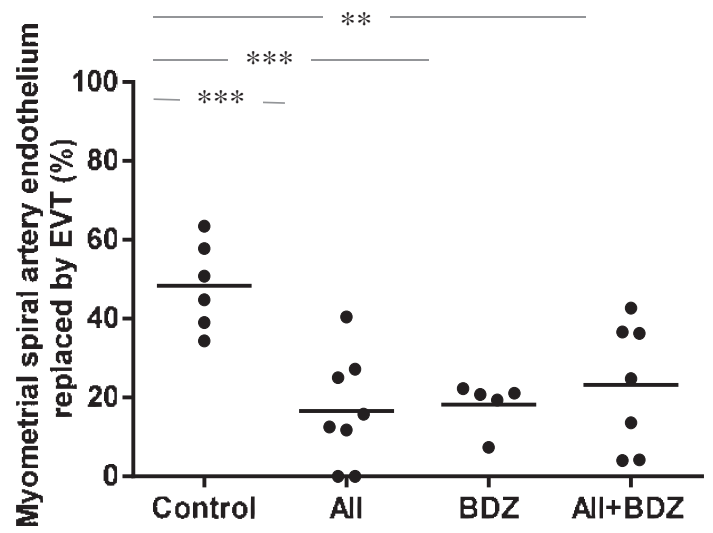

Figure 3 Intraluminal extravillous trophoblasts in spiral arteries on gestational day 60 in dams treated with saline, angiotensin II (All), Bradyzide (BDZ), or All + BDZ. (A) Lateral spiral artery endothelium replaced by extravillous trophoblasts (EVT) (\% perimeter) in dams treated with saline, All, BDZ, or All + BDZ. (B) Myometrial spiral artery endothelium replaced by EVT (\% perimeter) in dams treated with saline, All, BDZ, or All + BDZ. Continuous line represents mean values. ${ }^{* *} \mathrm{P}<0.005$; ${ }^{* *} \mathrm{P}<0.0005$

\section{Discussion}

The results of the present study indicate that a transient disruption of the balance between the RAS and the KKS in favor of the RAS in midpregnancy alters the maternal adaptation to pregnancy.

At the level of the utero-placental unit, tilting the RAS/ KKS balance towards vasoconstriction caused fetal losses and placental insufficiency, and reduced the replacement of endothelium by endovascular trophoblasts in the spiral arteries. Infusions were delivered between gestational days 20 and 34, which is when extravillous trophoblasts display the maximal decidual penetration [37]; thus the secondary fetal losses may be attributed to decreased decidual vasodilatation, hyperpermeability, and priming of the spiral arteries [41]. The retardation of trophoblast invasion, reflected at term by a reduction of endovascular trophoblasts in viable feto-placental units, was likely due to B2R blockade and excessive AT1R stimulation as observed in HTR-8/SVneo cells $[27,28]$. Guinea-pigs express AT1 and AT2 receptors in the placenta, decidua, and extravillous trophoblasts (Acuña and Valdés, unpublished observation), similar to what has been described in humans [26,32,42-45]. However, the deleterious effects of AT1R antagonists in pregnancy $[46,47]$ preclude their use for identifying the main receptor stimulated by excess angiotensin.

The acute effect of angiotensin II plus a B2R blocker provoked an increase of systolic blood pressure in a subset of the group (responders) to values that were not attained with single interventions and in non-pregnant females receiving the combined treatment. The responders are probably bradykinin-dependent when circulating angiotensin II surpasses the endogenous gestational levels.

This study leaves unresolved questions regarding why additive effects of combined interventions were observed for some, but not all, study parameters. The discordance between the lack of additive effect on fetal weight and the summatory impact on the fetal/placental weight ratio could be because the combined intervention induces greater fetal losses, which favor the growth of the remaining units. The higher plasma creatinine in dams that received BDZ-absent in the AII + BDZ group-could be attributed to a lack of the protective effect of $B 2 R$ in the face of gestational hyperfiltration [48], as reported in B2R-null mice [49]. In the AII + BDZ group, this could be compensated by positive regulation of $B d k r B 2$ gene expression by AII, and by AT1R-mediated activation of B2R expression [50]. These postulates exemplify how, in vivo, an intricate vasodilatory/pleiotropic network and tissue-specific effects could diminish the effects of angiotensin II stimulation and B2R blockade.

The presently observed persistent changes in trophoblast invasion partially confirm our hypothesis that disturbing the endogenous balance between the RAS and the KKS in mid-pregnancy would provoke a defective 


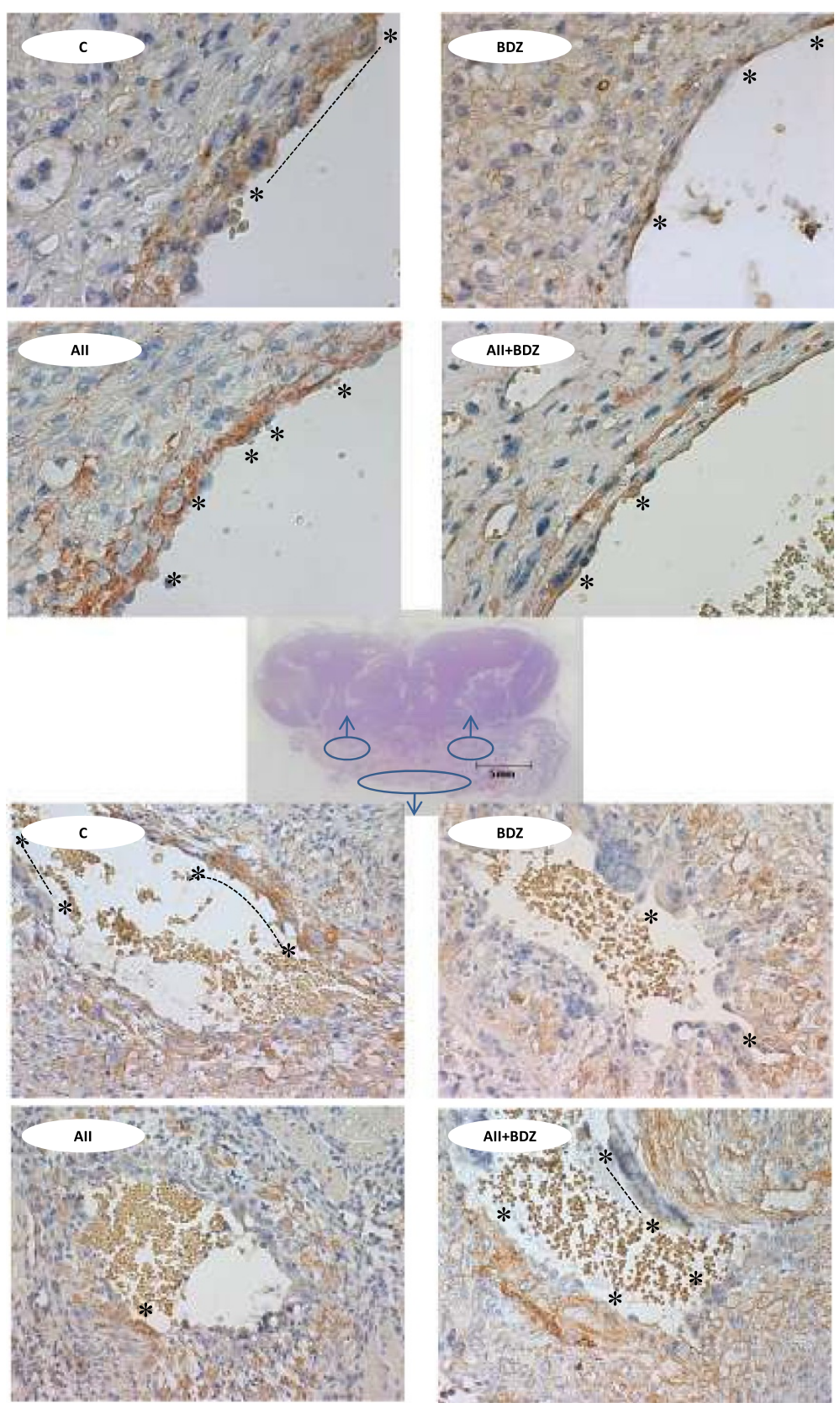

Figure 4 Representative sections of spiral arteries on day 60 of gestation in dams treated with saline (C), Bradyzide (BDZ), angiotensin II (AII) angiotensin II + Bradyzide (AII + BDZ). Endoluminal trophoblasts in lateral and myometrial spiral arteries are depicted in the upper and lower panel, respectively. The whole-mount haematoxylin/eosin section of the guinea-pig utero-placental interface includes in blue ovals the zones from which the microphotographs were acquired; trophoblasts were identified by anti-cytokeratin and highlighted by * and interrupted lines. Magnification ×400 in upper panel and x100 in lower panel.

trophoblast invasion. However, the preeclampsia phenotype was not reproduced. It remains to be tested whether dams would develop this syndrome if the interventions were continued to term. In humans, a maintained increase in circulating AII could correlate with the agonistic autoantibody to AT1R [23], the T235 polymorphism of the angiotensinogen gene [51], and the redox conformation of angiotensinogen that facilitates angiotensin release [24]. Decreased stimulation of the B2R by bradykinin could derive from a depressed KKS, as observed in women who present with pregnancy hypertension or preeclampsia $[52,53]$. Lastly, the AII + BDZ combination might resemble the heterodimerization of the AT1R and B2R, which sensitizes the AT1R and blunts the response of the B2R [19]. A 
persistent disequilibrium of the vasoconstrictor/vasodilator balance would be magnified along its course by the recruitment of intermediate effectors.

\section{Conclusions}

By transiently tilting the balance of the opposing RAS and KKS systems during the period of maximal trophoblast invasion, we demonstrated deleterious effects of AII and B2R blockade in pregnant guinea-pigs. Further understanding of the effects of the opposing RAS and KKS could inspire the development of pharmacological interventions to enhance the KKS in order to counteract excessive preponderance of AT1R activation in maternal circulation and the uteroplacental interface in preeclampsia, mediated by angiotensin II and the agonistic AT1R autoantibody. This study also demonstrates the feasibility of characterizing systemic and local modifications in the pregnant guinea-pig, supporting the use of this model in studies of normal placentation and related disorders.

\section{Competing interests}

The authors declare that they have no competing interests.

\section{Authors' contributions}

GV designed the study, participated in sample extraction and data analysis, drafted the manuscript and wrote its final version. DS and JC implanted the osmotic pumps, and performed blood pressure measurements and animal dissections. DS performed the immunohistochemistry, the digital processing of the images, and the statistical analysis. RO performed the ultrasonographies and Stephanie Acuña the acquisition of the microphotograhs. Oslando Padilla supervised the statistical analysis and performed the Bayesian statistics. With the exception of deceased JC, all authors read and approved the final manuscript.

\section{Acknowledgements}

This study was financed by Fondecyt 1080228 and 1121161. The authors are indebted to Ms. Marta Díaz and Eliana Lira for their contributions in the care and mating of the animals, and the preparation of the histological sections.

\section{Author details}

${ }^{1}$ Centro de Investigaciones Médicas, Escuela de Medicina, Pontificia Universidad Católica, Santiago, Chile. ${ }^{2}$ Departamento de Nefrología, Escuela de Medicina, Pontificia Universidad Católica, Santiago, Chile. ${ }^{3}$ Departamento de Salud Pública, Escuela de Medicina, Pontificia Universidad Católica, Santiago, Chile.

Received: 19 March 2014 Accepted: 25 May 2014

Published: 4 June 2014

\section{References}

1. Fyhrquist F, Saijonmaa O: Renin-angiotensin system revisited. J Intern Med 2008, 264:224-236.

2. Nguyen G, Delarue F, Burckle C, Bouzhir L, Giller T, Sraer JD: Pivotal role of the renin/prorenin receptor in angiotensin II production and cellular responses to renin. J Clin Invest 2002, 109:1417-1427.

3. Chen S, Patel JM, Block ER: Angiotensin IV-mediated pulmonary artery vasorelaxation is due to endothelial intracellular calcium release. Am J Physiol Lung Cell Mol Physiol 2000, 279:L849-L856.

4. Flores-Muñoz M, Smith NJ, Haggerty C, Milligan G, Nicklin SA: Angiotensin1-9 antagonises pro-hypertrophic signalling in cardiomyocytes via the angiotensin type 2 receptor. J Physiol 2011, 589:939-951.

5. Ocaranza MP, Jalil JE: Protective role of the ACE2/Ang-(1-9) axis in cardiovascular remodeling. Int J Hypertens 2012, 2012:594361.

6. Santos RA, Brosnihan KB, Jacobsen DW, DiCorleto PE, Ferrario CM: Production of angiotensin-(1-7) by human vascular endothelium. Hypertension 1992, 19:||56-||61.
7. Santos RA, Simoes e Silva AC, Maric C, Silva DM, Machado RP, de Buhr I, Heringer-Walther S, Pinheiro SV, Lopes MT, Bader M, Mendes EP, Lemos VS, Campagnole-Santos MJ, Schultheiss HP, Speth R, Walther T: Angiotensin-(1-7) is an endogenous ligand for the $\mathrm{G}$ protein-coupled receptor Mas. Proc Natl Acad Sci USA 2003, 100:8258-8263.

8. Koumandou VL, Scorilas A: Evolution of the plasma and tissue kallikreins, and their alternative splicing isoforms. PLOS One 2013, 8:e68074.

9. Gainer JV, Morrow JD, Loveland A, King DJ, Brown NJ: Effect of bradykininreceptor blockade on the response to angiotensin-converting-enzyme inhibitor in normotensive and hypertensive subjects. N Engl J Med 1998, 339:1285-1292.

10. Witherow FN, Helmy A, Webb DJ, Fox KA, Newby DE: Bradykinin contributes to the vasodilator effects of chronic angiotensin-converting enzyme inhibition in patients with heart failure. Circulation 2001, 104:2177-2181.

11. Gavras I: Bradykinin-mediated effects of ACE inhibition. Kidney Int 1992, 42:1020-1029.

12. Cockcroft JR, Chowienczyk PJ, Brett SE, Bender N, Ritter JM: Inhibition of bradykinin-induced vasodilation in human forearm vasculature by icatibant, a potent B2-receptor antagonist. Br J Clin Pharmacol 1994, 38:317-321.

13. Celerier J, Cruz A, Lamande N, Gasc JM, Corvol P: Angiotensinogen and its cleaved derivatives inhibit angiogenesis. Hypertension 2002, 39:224-228.

14. Pendergrass KD, Gwathmey TM, Michalek RD, Grayson JM, Chappell MC: The angiotensin II-AT1 receptor stimulates reactive oxygen species within the cell nucleus. Biochem Biophys Res Commun 2009, 384:149-154.

15. Savard M, Barbaz D, Belanger S, Müller-Esterl W, Bkaily G, D'Orleans-Juste P, Cote J, Bovenzi V, Gobeil F Jr: Expression of endogenous nuclear bradykinin B2 receptors mediating signaling in immediate early gene activation. J Cell Physiol 2008, 216:234-244

16. Schmaier AH: The kallikrein-kinin and the renin-angiotensin systems have a multilayered interaction. Am J Physiol Regul Integr Comp Physiol 2003, 285:R1-R13.

17. Su JB: Different cross-talk sites between the renin-angiotensin and the kallikrein-kinin systems. J Renin Angiotensin Aldosterone Syst 2013, doi:10.1177/1470320312474854

18. AbdAlla S, Abdel-Baset A, Lother H, el Massiery A, Quitterer U: Mesangial AT1/ B2 receptor heterodimers contribute to angiotensin II hyperresponsiveness in experimental hypertension. J Mol Neurosci 2005, 26:185-192.

19. AbdAlla S, Lother $\mathrm{H}$, el Massiery A, Quitterer U: Increased AT(1) receptor heterodimers in preeclampsia mediate enhanced angiotensin II responsiveness. Nat Med 2001, 7:1003-1009.

20. Quitterer $\mathrm{U}$, Lother $\mathrm{H}$, Abdalla S: AT1 receptor heterodimers and angiotensin II responsiveness in preeclampsia. Semin Nephrol 2004, 24:115-119.

21. Quitterer U, Abdalla S: Vasopressor meets vasodepressor: the AT1-B2 receptor heterodimer. Biochem Pharmacol 2014, 88:284-290.

22. Valdés G, Kaufmann P, Corthorn J, Erices R, Brosnihan KB, Joyner-Grantham J: Vasodilator factors in the systemic and local adaptations to pregnancy. Reprod Biol Endocrinol 2009, 7:79.

23. Wallukat G, Homuth V, Fischer T, Lindschau C, Horstkamp B, Jupner A, Baur E, Nissen E, Vetter K, Neichel D, Dudenhausen JW, Haller H, Luft FC: Patients with preeclampsia develop agonistic autoantibodies against the angiotensin AT1 receptor. J Clin Invest 1999, 103:945-952.

24. Zhou A, Carrell RW, Murphy MP, Wei Z, Yan Y, Stanley PL, Stein PE, Broughton Pipkin F, Read RJ: A redox switch in angiotensinogen modulates angiotensin release. Nature 2010, 468:108-111.

25. Lumbers ER, Pringle KG: Roles of the circulating renin-angiotensin-aldosterone system in human pregnancy. Am J Physiol Regul Integr Comp Physiol 2014 306:R91-R101.

26. Herse F, Dechend R, Harsem NK, Wallukat G, Janke J, Qadri F, Hering L, Muller DN Luft FC, Staff AC: Dysregulation of the circulating and tissue-based renin-angiotensin system in preeclampsia. Hypertension 2007, 49:604-611.

27. Xia Y, Wen HY, Kellems RE: Angiotensin II inhibits human trophoblast invasion through AT1 receptor activation. J Biol Chem 2002, 277:24601-24608,

28. Erices R, Corthorn J, Lisboa F, Valdés G: Bradykinin promotes migration and invasion of human immortalized trophoblasts. Reprod Biol Endocrinol 2011, 9:97.

29. Kaufmann P, Davidoff M: The guinea-pig placenta. Adv Anat Embryol Cell Biol 1977, 53:5-91.

30. Mitchell BF, Taggart MJ: Are animal models relevant to key aspects of human parturition? Am J Physiol Regul Integr Comp Physiol 2009, 297:R525-R545. 
31. Seidl DC, Hughes HC, Bertolet R, Lang CM: True pregnancy toxemia (preeclampsia) in the guinea pig (Cavia porcellus). Lab Anim Sci 1979, 29:472-478.

32. Anton L, Merrill DC, Neves LA, Diz DI, Corthorn J, Valdés G, Stovall K, Gallagher PE, Moorefield C, Gruver C, Brosnihan KB: The uterine placental bed renin-angiotensin system in normal and preeclamptic pregnancy. Endocrinology 2009, 150:4316-4325.

33. Valdés G, Corthorn J, Bharadwaj MS, Joyner J, Schneider D, Brosnihan KB: Utero-placental expression of angiotensin-(1-7) and ACE2 in the pregnant guinea-pig. Reprod Biol Endocrinol 2013, 11:5.

34. Welsh T, Mitchell CM, Walters WA, Mesiano S, Zakar T: Prostaglandin H2 synthase- 1 and -2 expression in guinea-pig gestational tissues during late pregnancy and parturition. J Physiol 2005, 569:903-912.

35. Valdés G, Neves LA, Anton L, Corthorn J, Chacón C, Germain AM, Merrill DC, Ferrario CM, Sarao R, Penninger J, Brosnihan KB: Distribution of angiotensin-(1-7) and ACE2 in human placentas of normal and pathological pregnancies. Placenta 2006, 27:200-207.

36. Valdés G, Erices R, Chacón C, Corthorn J: Angiogenic, hyperpermeability and vasodilator network in utero-placental units along pregnancy in the guinea-pig (Cavia porcellus). Reprod Biol Endocrinol 2008, 6:13.

37. Corthorn J, Rey S, Chacon C, Valdés G: Spatio-temporal expression of MMP-2, MMP-9 and tissue kallikrein in uteroplacental units of the pregnant guinea-pig (Cavia porcellus). Reprod Biol Endocrinol 2007, 5:27.

38. Burgess GM, Perkins MN, Rang HP, Campbell EA, Brown MC, Mclntyre P, Urban L, Dziadulewicz EK, Ritchie TJ, Hallett A, Snell CR, Wrigglesworth R, Lee W, Davis C, Phagoo SB, Davis AJ, Phillips E, Drake GS, Hughes GA, Dunstan A, Bloomfield GC: Bradyzide, a potent non-peptide B(2) bradykinin receptor antagonist with long-lasting oral activity in animal models of inflammatory hyperalgesia. Br J Pharmacol 2000, 129:77-86.

39. Fowden AL, Sferruzzi-Perri AN, Coan PM, Constancia M, Burton GJ: Placental efficiency and adaptation: endocrine regulation. J Physiol 2009, 587:3459-3472.

40. Matthews RAJ: Methods for assessing the credibility of clinical trial outcomes. Drug Inf J 2001, 35:1469-1478.

41. Nanaev A, Chwalisz K, Frank HG, Kohnen G, Hegele-Hartung C, Kaufmann P: Physiological dilation of uteroplacental arteries in the guinea pig depends on nitric oxide synthase activity of extravillous trophoblast. Cell Tissue Res 1995, 282:407-421.

42. Tower CL, Lui S, Charlesworth NR, Smith SD, Aplin JD, Jones RL: Differential expression of angiotensin II type 1 and type 2 receptors at the maternal-fetal interface: potential roles in early placental development. Reproduction 2010, 140:931-942.

43. Anton L, Brosnihan KB: Systemic and uteroplacental renin-angiotensin system in normal and pre-eclamptic pregnancies. Ther Adv Cardiovasc Dis 2008, 2:349-362

44. Pringle KG, Tadros MA, Callister RJ, Lumbers ER: The expression and localization of the human placental prorenin/renin-angiotensin system throughout pregnancy: roles in trophoblast invasion and angiogenesis? Placenta 2011, 32:956-962.

45. Williams PJ, Mistry HD, Innes BA, Bulmer JN, Broughton Pipkin F: Expression of AT1R, AT2R and AT4R and their roles in extravillous trophoblast invasion in the human. Placenta 2010, 31:448-455.

46. Broughton Pipkin F, Symonds EM, Turner SR: The effect of captopril $(S Q 14,225)$ upon mother and fetus in the chronically cannulated ewe and in the pregnant rabbit. J Physiol 1982, 323:415-422.

47. Hanssens M, Keirse MJ, Vankelecom F, Van Assche FA: Fetal and neonatal effects of treatment with angiotensin-converting enzyme inhibitors in pregnancy. Obstet Gynecol 1991, 78:128-135.

48. Cadnapaphornchai MA, Ohara M, Morris KG Jr, Knotek M, Rogachev B, Ladtkow T, Carter EP, Schrier RW: Chronic NOS inhibition reverses systemic vasodilation and glomerular hyperfiltration in pregnancy. Am J Physiol Renal Physiol 2001, 280:F592-F598.

49. Tomita H, Sanford RB, Smithies O, Kakoki M: The kallikrein-kinin system in diabetic nephropathy. Kidney Int 2012, 81:733-744

50. Shen B, Harrison-Bernard LM, Fuller AJ, Vanderpool V, Saifudeen Z, El-Dahr SS: The bradykinin B2 receptor gene is a target of angiotensin II type 1 receptor signaling. J Am Soc Nephrol 2007, 18:1140-1149.
51. Ward K, Hata A, Jeunemaitre X, Helin C, Nelson L, Namikawa C, Farrington PF, Ogasawara M, Suzumori K, Tomoda S, Berrebi S, Sasaki M, Corvol P, Lifton RP, Lalouel JM: A molecular variant of angiotensinogen associated with preeclampsia. Nat Genet 1993, 4:59-61.

52. Elebute $\mathrm{OA}$, Mills $\mathrm{H}$ : Urinary kallikrein in normal and hypertensive pregnancies. Perspect Nephrol Hypertens 1976, 5:329-338.

53. Millar JG, Campbell SK, Albano JD, Higgins BR, Clark AD: Early prediction of pre-eclampsia by measurement of kallikrein and creatinine on a random urine sample. Br J Obstet Gynaecol 1996, 103:421-426.

doi:10.1186/1477-7827-12-49

Cite this article as: Valdés et al:: Administration of angiotensin II and a bradykinin B2 receptor blocker in midpregnancy impairs gestational outcome in guinea pigs. Reproductive Biology and Endocrinology 2014 12:49.

\section{Submit your next manuscript to BioMed Central and take full advantage of:}

- Convenient online submission

- Thorough peer review

- No space constraints or color figure charges

- Immediate publication on acceptance

- Inclusion in PubMed, CAS, Scopus and Google Scholar

- Research which is freely available for redistribution 